Journal of Essential Oil Bearing Plants (2018)

Post-Print

\title{
Study of Antifungal, Anti-aflatoxigenic, Antioxidant Activity and Phytotoxicity of Algerian Citrus limon var. Eureka and Citrus sinensis var. Valencia Essential oils
}

\author{
Yamina Ben Miri ${ }^{1}$, Agustín Ariño ${ }^{2}$ and Djamel Djenane ${ }^{1 *}$ \\ ${ }^{1}$ Laboratoire de Qualité et Sécurité des Aliments (LQSA), \\ University of Mouloud MAMMERI, P.O. Box 17. 15000. Tizi-Ouzou. Algeria \\ ${ }^{2}$ Instituto Agroalimentario de Aragón-IA2 (Universidad de Zaragoza-CITA), \\ Veterinary Faculty, 50013 Zaragoza, Spain \\ *Corresponding authors (Djamel Djenane) E-mail: < djenane6@yahoo.es >
}

\begin{abstract}
The inhibitory influence of Citrus limon var. Eureka and Citrus sinensis var. Valencia essential oils (EOs) on the growth of Aspergillus flavus and $\mathrm{AFB}_{1}$ production was evaluated. The EOs were characterized by limonene ( $54.95 \%$ and $82.6 \%$, respectively) as predominant component. Citrus limon EO at $1.75 \mathrm{mg} / \mathrm{mL}$ and Citrus sinensis at $2 \mathrm{mg} / \mathrm{mL}$ could totally inhibit fungal growth as well as AFB production. The Citrus EOs revealed wide spectrum of fungitoxicity against some isolated fungi in terms of MIC and MFC. On the other hand, the antioxidant activity was also assessed where IC50 and $\beta$-carotene/linoleic acid inhibition percentage of Citrus limon and Citrus sinensis oils were 1570.10 and $752.26 \mu \mathrm{g} / \mathrm{mL}, 36.19$ and $55.56 \%$, respectively, while the total phenolic were 16.90 and $10.53 \mu \mathrm{g} / \mathrm{mg}$, respectively. Additionally, the EOs showed their non phytotoxicity on wheat seeds. These findings demonstrated that EOs could be good alternatives to protect food.
\end{abstract}

Key words: Citrus essential oil, Aspergillus flavus, antifungal, aflatoxin $\mathrm{B}_{1}$, antioxidant, phytotoxicity.

\section{Introduction}

Mycotoxins are secondary metabolites that are not necessary to fungi growth. These toxins contaminate cereals, fruits, nuts, almonds, grains, as well as foods or compounds intended for human and animal consumption ${ }^{1}$.

The mycotoxins are secreted by fungi belonging to Aspergillus, Penicillium and Fusarium. Among these secondary metabolites considered important from an agriculture and health point of view, aflatoxins, which are produced by two strains of Aspergillus. Aspergillus flavus produces aflatoxins $\mathrm{B}_{1}\left(\mathrm{AFB}_{1}\right)$ and $\mathrm{B}_{2}\left(\mathrm{AFB}_{2}\right)$, while $A$. parasiticus excretes, in addition, aflatoxins $\mathrm{G}_{1}$ $\left(\mathrm{AFG}_{1}\right)$ and $\mathrm{G}_{2}\left(\mathrm{AFG}_{2}\right)$. A. nomius, close to $A$. flavus, is capable of producing aflatoxins. The most toxic of the four natural aflatoxins is $\mathrm{AFB}_{1}$. $\mathrm{AFB}_{1}$ is metabolized by cytochrome $\mathrm{P} 450$ to AFB1-8, 9-epoxide that interacts with proteins and DNA inducing cell damages ${ }^{2}$.

The development of methods for the decontamination of infested food items has become one of the major goals to ensure food safety for humans and animals. There are no specialized methods that would remove all mycotoxins. Strategies are classified according to whether they are based on chemical, physical and biological processes. They must either reduce toxins or degrade them without producing residual toxicities, developing of resistant microorganisms or decreasing the organoleptic and nutritional proprieties of food.

A new approach has been developed by using 
natural products to decrease the fungal growth and mycotoxin contamination in food ${ }^{3}$. Essential oils (EOs) produced by such plants as Carum carvi L., Thymus vulgaris, Citrus aurantifolia and Cinnamomum zeylanicum L. EOs have been supported because of their antimicrobial activity

${ }^{4-5}$. EOs are liquids obtained by hydro-distillation method from different parts of plant and composed of variety of bioactive components that is why they are interesting in antimicrobial activity. The application of EOs is in demand by consumer to preserve foods because they are generally recognized as safe (GRAS) ${ }^{6}$.

The present study investigated the antifungal, antiaflatoxin, total phenolic content, antioxidant activity and phytotoxicity of Citrus limon var. Eureka (lemon) and Citrus sinensis var. Valencia (orange) EOs.

\section{Materials and methods Chemicals and equipment}

Chemical products and solvents used in the study were obtained from different companies in different countries: chloroform, methanol, dimethyl sulfoxide (DMSO), isoamyl alcohol, hexane, anhydrous sodium sulphate $\left(\mathrm{Na}_{2} \mathrm{SO}_{4}\right)$, linoleic acid, Folin-Ciocalteu, $\mathrm{Na}_{2} \mathrm{CO}_{3}$, gallic acid, butylated hydroxytoluene (BHT), Potato Dextrose Agar (PDA) medium (Potato, $200 \mathrm{~g}$; Dextrose, $20 \mathrm{~g}$; Agar, $15 \mathrm{~g}$ and distilled water $1000 \mathrm{~mL}$ ), Malt Extract Agar (M.E.A) (Malt extract, 20 g; Peptone, $1 \mathrm{~g}$; Glucose, $20 \mathrm{~g}$; Agar, $20 \mathrm{~g}$; Distilled water, $1000 \mathrm{~mL})$, Czapek concentrate $\left(\mathrm{N}_{\mathrm{a}} \mathrm{NO}_{3}, 30 \mathrm{~g}\right.$; $\mathrm{KCl}, 5 \mathrm{~g}$; $\mathrm{MgSO}_{4} .7 \mathrm{H}_{2} \mathrm{O}, 5 \mathrm{~g}$; $\mathrm{FeSO}_{4} .7 \mathrm{H}_{2} \mathrm{O}, 0.1 \mathrm{~g}$; Distilled water, $1000 \mathrm{~mL}$ ), Glycerol Nitrate Agar (G25N) $\left(\mathrm{K}_{2} \mathrm{HPO}_{4}, 0.75 \mathrm{~g}\right.$; Czapek concentrate, $7.5 \mathrm{~mL}$; Yeast extract, $3.7 \mathrm{~g}$; Glycerol, $250 \mathrm{~g}$; Agar, $12 \mathrm{~g}$; Distilled water $750 \mathrm{~mL}$ ), Aspergillus flavus and parasiticus agar (AFPA) (Peptone, $10 \mathrm{~g}$; Yeast extract, $20 \mathrm{~g}$; Ferric ammonium citrate, 0.5 g; Chloramphenicol, 100 mg;Agar, 15 g; Dichloran, $2 \mathrm{mg}$; Distilled water, $1000 \mathrm{~mL}$ ), SMKY medium; (Sucrose, $200 \mathrm{~g} ; \mathrm{MgSO}_{4} \cdot 7 \mathrm{H}_{2} \mathrm{O}, 0.5 \mathrm{~g} ; \mathrm{KNO}_{3}, 0.3$ $\mathrm{g}$ and yeast extract, $7 \mathrm{~g}$; $1000 \mathrm{ml}$ distilled water) were obtained from Sigma-Aldrich (France). Tween 40 and tween-80 from Sigma-Aldrich (Germany). 2,2-diphenyl-1-picrylhydrazil (DPPH) and $\beta$-carotene were purchased from SigmaAldrich (Netherland). Silica gel-G 60 from Fluka
(Germany).

Hydro-distillation apparatus, GC-MS (Agilent Technologies; model 6850 and 5973, United Kingdom), centrifugation apparatus (Jouan E76, United Kingdom), UV lamp (CN-6, Vilber Lourmay, France), spectrophotometer (6705 UV/Vis, Jenway, United Kingdom) and a light microscope (Motic: BA210, China) were used in the present investigation.

\section{Plant material}

The fruits of $C$. limon var. Eureka and $C$. sinensis var. Valencia were harvested from the experimental field of the Institute of fruit-farming technology, in Mitidja province, in Algeria, in March and April 2015. Botanical authentication of the species was given by the same Institute.

\section{Extraction of essential oils}

EOs were extracted from C. limon and $C$. sinensis peels ( $200 \mathrm{~g})$ by hydrodistillation at atmospheric pressure, using a Clevenger type apparatus for $4 \mathrm{~h}$. The obtained EOs were dried with anhydrous sodium sulphate $\left(\mathrm{Na}_{2} \mathrm{SO}_{4}\right)$ and then recovered, weighed and stored in brown vials, hermetically sealed and stored at $4^{\circ} \mathrm{C}$ before being used.

\section{Essential oil analysis \\ Gas chromatography-Mass spectrometry (GC- MS) analysis}

The chemical composition of the EO was analyzed using GC-MS. The EO $(10 \mu \mathrm{L})$ was dissolved in hexane $(100 \mu \mathrm{L})$ and $2 \mu \mathrm{L}$ of the solution was injected into a GC-MS (Agilent; model 6850 and 7890). The capillary column was DB-5 (length $=30 \mathrm{~m} \times 0.25 \mathrm{~mm}$ i.d., film thickness $=$ $0.25 \mu \mathrm{m})$. Helium was used as the carrier gas at a flow rate of $1.0 \mathrm{~mL} / \mathrm{min}$. The column inlet pressure was $8.07 \mathrm{psi}$. The GC column oven temperature was increased from 60 to $245^{\circ} \mathrm{C}$ at $3^{\circ} \mathrm{C} / \mathrm{min}$, with a final hold time of $4 \mathrm{~min}$. The Electron Ionization-Mass Spectrometry (EI-MS) operating parameters were as follows: electron energy, $70 \mathrm{eV}$; automatic scanning of the mass range 50-550 amu; ion source temperature, $230^{\circ} \mathrm{C}$; quadrupole, $150^{\circ} \mathrm{C}$.

The identification of the volatile compounds was done by comparing the mass spectra (MS) ob- 
tained with the NIST electronic databases, as well as with the bibliography ${ }^{7}$ in parallel with the use of retention indices (IR) based on series of $n$ alkane indices (C8-C28) on the capillary column.

\section{Fungal material and confirmation of testing strain}

A. flavus E73 was obtained from Laboratoire de Biologie des Systmes Microbiens (LBSM; Kouba; Algeirs; Algeria). Confirmation of strain was realized according to the morphological characteristics of the mycelium, by microscopic observation, and single spore method after their culture on Malt Extract Agar (M.E.A), Glycerol Nitrate Agar (G25N) and Czapek Yeast Agar (C.Y.A), the confirmation was also carried out by inoculation in A. flavus and parasiticus agar (AFAP) medium. This medium confirms that it belongs to the group A. flavus. In this medium the color of the reverse side of the colony is yellow-orange ${ }^{8}$. Afterwards, A. flavus E73 was maintained on Potato Dextrose Agar (PDA) at $4^{\circ} \mathrm{C}$. Some other fungi viz. A. carbonarius, A. fumigatus, A. niger, A. ochraceus, A. tamarii, A. terreus, Fusarium sp., Penicillium sp., Rhizopus sp., isolated during mycological analysis of some edibles (spices and cereals) in our labora-tory in order their fungitoxicity spectrum.

\section{Test confirming the aflatoxinogenicity of the strain}

The method consisted in cultivating the $A$. flavus E73 (disc of $6 \mathrm{~mm}$ diameter) strain in Erlenmeyer flask containing $25 \mathrm{~mL}$ of the Sucrose Potassium nitrate Magnesium sulfate Yeast (SMKY) liquid medium for 10-day incubation period at $28 \pm 2{ }^{\circ} \mathrm{C}$. The content was filtered (Whatman no.1) and extracted with 20 $\mathrm{mL}$ chloroform. After stirring and then decanting, the chloroform phase was recovered, evaporated and redissolved in $1 \mathrm{~mL}$ chloroform. A volume of $50 \mu \mathrm{L}$ of sample was spotted on a thin layer chromatography (TLC). The development of the chromatograms was car-ried out in a standard tank $(20 \times 20 \mathrm{~cm})$ previ-ously saturated with the solvent system: toluene: iso-amyl alcohol: methanol (90: 32: 2; $\mathrm{v} / \mathrm{v} / \mathrm{v}$ ). After migration, the plates was removed and dried at $60^{\circ} \mathrm{C}$ for $24 \mathrm{~h}$. AFB1 were detected by placing the plate in UV transilluminator $(360 \mathrm{~nm})$. The AFB1 appeared as a blue spot. The intensity of the fluorescence of the spots confirmed the pres-ence of AFB1 9 .

\section{Preparation of fungal spore suspension}

The spores of A. flavus E73 grown on PDA medium (culture of 7 days) were recovered by washing the Petri dish with a volume of $20 \mathrm{~mL}$ of $0.1 \%$ tween 80 sterile solution. The suspension was then filtered through sterile muslin tissue. Spore concentration $\left(1 \times 10^{6} \mathrm{spores} / \mathrm{mL}\right)$ was determined by Mallassez cell (depth $0.2 \mathrm{~mm}, 1 / 400$ $\mathrm{mm}^{2}$ ) under a light microscope. The number of spores of $1 \times 10^{6} / \mathrm{mL}$ was fixed throughout our study.

\section{In vitro antifungal activity of $C$. limon and $C$. sinensis EOs}

The evaluation of the activity of $C$. limon and $C$. sinensis EOs on the mycelial growth of $A$. flavus E73 was carried out using the direct contact technique. The method of the poisoned medium used to test the sensitivity of the fungal strain to the different EOs was that of Singh ${ }^{10}$ and José Velázquez-Nuñez et al. ${ }^{11}$. EOs were added to $10 \mathrm{~mL}$ PDA and mixed at $45-50^{\circ} \mathrm{C}$ in Petri dishes to obtain final concentrations ranging from 0.25 to $2 \mathrm{mg} / \mathrm{mL}$ selected after preliminary tests. After solidification of the medium in each Petri dish, $10 \mu \mathrm{L}$ of a suspension of $1 \times 10^{6}$ spores $/ \mathrm{mL}$ was deposited in the center of each Petri dish. The control plates were prepared in parallel without EO. The plates were incubated at $28 \pm 2^{\circ} \mathrm{C}$. Three repetition of each treatment were carried out. The mycelial growth was followed by measuring the diameter of two straight lines perpendicular to the center. Measurements were made every day for 7 days. The comparison of the dimensions obtained with those of the controls made it possible to calculate the percentage inhibition (I \%) at day 7 , according to the following formula:

$$
\mathrm{I} \%=\left(1-\frac{\mathrm{Da}}{\mathrm{Db}}\right) \times 100
$$

Where Da: the diameter of the zone of growth of the test in $\mathrm{cm} ; \mathrm{Db}$ : the diameter of the growth zone of the control in $\mathrm{cm}$. 


\section{Determination of minimum inhibitory concen- tration (MIC and minimum fungicidal con- centration (MFC}

The MIC and MFC for A. flavus E73 were determined by broth dilution using the method of Shukla et al. ${ }^{12}$. Different concentrations of C. limon and C. sinensis EOs ( 0.25 to $2 \mathrm{mg} / \mathrm{mL}$ ) were added to $10 \mathrm{~mL}$ SMKY medium in test tubes. Tubes with only SMKY medium used as control. The tubes were inoculated with spore suspension and incubated at $28 \pm 2{ }^{\circ} \mathrm{C}$ for 7 days. The lowest concentration of EOs capable of inhibiting the growth in test tubes during 7 days was considered as the MIC. After 7 days, the test tubes where the inhibition was total subcultured in Petri dishes containing fresh PDA. When there was a resumption of mycelial growth, the concentration was considered as the MFC.

Anti-aflatoxin test of $C$. limon and $C$. sinensis EOs

According to Mishra et al. ${ }^{9}$, suspensions (50 $\mu \mathrm{L}$ ) of A. flavus E73 were inoculated in $25 \mathrm{~mL}$ of SMKY medium supplemented with different concentrations of each EO. Cultures were incubated at $28 \pm 2{ }^{\circ} \mathrm{C}$. SMKY broth containing only $50 \mu \mathrm{L}$ of spore suspension as a control. Three repetition of each treatment were done. For the extrac-tion of $\mathrm{AFB}_{1}$, the same procedure was followed as described in section of test confirming the aflatoxinogenicity of the strain. The mycelia pro-duced in the liquid cultures were removed and washed on Whatman No. 1 filter paper. The weight of the mycelium was determined after desiccation at $80^{\circ} \mathrm{C}$ for 12 h. For the quantifica-tion of $\mathrm{AFB}_{1}$, the blue spots on TLC plates were scraped out, dissolved in $5 \mathrm{~mL}$ cold methanol and centrifuged at $2000 \mathrm{~g}$ for $5 \mathrm{~min}$. The absorbance of the supernatant was made using a UV-Visible spectrophotometer at $360 \mathrm{~nm}$. The quantity of $\mathrm{AFB}_{1}$ was calculated according to the formula by Tian et al. ${ }^{13}$ :

$\mathrm{AFB}_{1}$ content $\mu \mathrm{g} / \mathrm{mL}=(\mathrm{D} \times \mathrm{M}) /(\mathrm{E} \times \mathrm{l}) \times 1000$

Where $\mathrm{D}$ is the absorbance, $\mathrm{M}$ is the molecular weight of $\mathrm{AFB}_{1}(312 \mathrm{~g} / \mathrm{mol}), \mathrm{E}$ is the molar extinc-tion coefficient $(21,800 \quad 1 /$ mol.cm), and 1 is the path length $(1 \mathrm{~cm}$ cell was used).
$\mathrm{AFB}_{1}$ inhibition was also calculated as follows:

$$
\mathrm{I} \%=(1 \mathrm{X} / \mathrm{Y}) \times 100
$$

Where $\mathrm{X}(\mu \mathrm{g} / \mathrm{mL})$ is the mean concentration of $\mathrm{AFB}_{1}$ in the treatment and $\mathrm{Y}(\mu \mathrm{g} / \mathrm{mL})$ is the mean concentration of $\mathrm{AFB}_{1}$ in the control.

\section{Spectrum of fungitoxicity of $C$. limon and $C$. sinensis EOs}

The MIC and MFC of EOs against some isolated fungi viz. A. carbonarius, A. fumigatus, $A$. niger, A. ochraceus, A. tamarii, A. terreus, Fusarium sp., Penicillium sp., Rhizopus sp., was evaluated by using SMKY medium at the selected concentrations ( 0.5 to $2 \mathrm{mg} / \mathrm{mL}$ ) as described before to record their fungitoxic spectrum.

\section{Determination of total phenolic content of EOs}

As reported by Dewanto et al. ${ }^{14}, 125 \mu \mathrm{L}$ of EOs in DMSO was dissolved in $500 \mu \mathrm{L}$ of distilled wa-ter and $125 \mu \mathrm{L}$ of Folin-Ciocalteu reagent 10 times diluted. The mixture was agitated and incubated for $3 \mathrm{~min}$, and then 1.25 $\mathrm{mL}$ of $7 \% \mathrm{Na}_{2} \mathrm{CO}_{3}$ was added, adjusting with distilled water to $3 \mathrm{~mL}$. Af-ter incubation for $2 \mathrm{~h}$ at $25 \pm 2{ }^{\circ} \mathrm{C}$, the absorbance at $760 \mathrm{~nm}$ was measured. The same procedure was also applied to the standard solutions of gal-lic acid $(25-200 \mu \mathrm{g} / \mathrm{mL})$. The concentration of total phenolic contents of the oils was calculated from the regression equation of the curve established with the standard gallic acid and expressed in micrograms of equivalents, gallic acid per milli-gram of EO. All tests were carried out in tripli-cate.

\section{Antioxidant activity \\ DPPH free radical scavenging assay}

The test evaluates the capacity of the EO to scavenge 2, 2-diphenyl 1-picrylhydrazil radical (DPPH). Briefly, in clean and dry tubes, volumes of $50 \mu \mathrm{L}$ of different concentrations $(100,200,400,600,800$ and $1000 \mu \mathrm{g} / \mathrm{mL})$ of each EO and standard BHT were added to 5 $\mathrm{mL}$ of $0.004 \%(\mathrm{w} / \mathrm{v})$ methanolic solution of DPPH and incubated in darkness at room temperature for $30 \mathrm{~min}$. Thereafter their absorbances were measured against a blank at $517 \mathrm{~nm}$ by spectrophotometer 
15. DPPH radical-scavenging activity was expressed in terms of inhibition percentage (I \%) and was calculated using the following formula :

$$
\mathrm{I} \%=\left(\mathrm{A}_{\text {blank__ }} \mathrm{A}_{\text {sample }} / \mathrm{A}_{\text {blank }}\right) \times 100
$$

$\mathrm{A}_{\text {blank }}$ is the absorbance of the control, and $\mathrm{A}_{\text {sample }}$ is the absorbance of the sample.

The value of the inhibitory concentration $\left(\mathrm{IC}_{50}\right)$ represents the dose of the $\mathrm{EO}$ which causes the neutralization of $50 \%$ of the DPPH radicals. $\mathrm{IC}_{50}$ was estimated by extrapolation by plotting the percent inhibition (I \%) versus concentration curves. All tests were performed in triplicate.

Beta-carotene/linoleic acid bleaching assay

This complementary method is used to assess the antioxidant activity of compounds. As described by Miraliakbari and Shahidi ${ }^{16}, 0.5 \mathrm{mg}$ of $\beta$-carotene was dissolved in $1 \mathrm{~mL}$ of chloroform, $25 \mu \mathrm{L}$ of linoleic acid and $200 \mathrm{mg}$ Tween 40 . The chloroform was totally evaporated; then $100 \mathrm{~mL}$ of aerated distilled water was added and the mixture was shaken. The samples $(2 \mathrm{~g} / \mathrm{L})$ were dissolved in DMSO and $350 \mu \mathrm{L}$ of each sample solution were added to $2.5 \mathrm{~mL}$ of the resulted mixture and incubated in water bath at $50{ }^{\circ} \mathrm{C}$; for $2 \mathrm{~h}$ with controls. BHT was used as a positive control and DMSO as a negative control. The absorbance was measured at $470 \mathrm{~nm}$ by spectrophotometer and the antioxidant activities (I \%) was calculated using the following formula:

$$
\begin{aligned}
& \mathrm{I} \%=\left(\mathrm{A}_{\beta \text {-Carotene after } 2 \mathrm{~h} \text { assay }} / \mathrm{A}_{\text {initial } \beta \text {-Caro- }}\right. \\
& \text { tene }) \times 100
\end{aligned}
$$

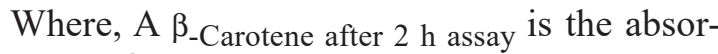
bance of $\beta$-Carotene after $2 \mathrm{~h}$ assay and $A$ initial $\beta$-Carotene is the absorbance of $\beta$-Carotene at the beginning of the experiments. All tests were carried out in triplicate.

\section{Phytotoxicity assay of $C$. limon and $C$. sinensis EOs}

The phytotoxicity of EOs was determined for varieties of Triticum aestivum (wheat) viz. AS 81189 A (Ain Abid) and HD 1220 (Hiddab) (Dar El Beida, Algiers, Algeria) following the method proposed by Kordali et al. ${ }^{17}$. After surfacesterilising of wheat seeds with sodium hypochlo- rite ( $1 \%$ ) for $20 \mathrm{~min}$, rinsing and removing empty and undeveloped seeds. Two layers of filter paper were placed on each Petri plate and then 10 $\mathrm{mL}$ of distilled water were poured. Afterwards, 50 wheat seeds were deposited on the filter paper. Ten microliters $(10 \mu \mathrm{L})$ of each EO was dropped on Whatman no.1 and placed on the lid. Controls were also prepared but no EO was added. Petri plates were closed with parafilm and incubated at $23 \pm 2^{\circ} \mathrm{C}$. After 8 days of incubation, the experiment was stopped and the percentage of germination of each variety was determined. The germination rate corresponds to the maximum percentage of germinated seeds in relation to the total seed number. After determining the number of seeds that germinated, the lengths of the radicle and the plumule were measured. Triplicates were carried out for each variety.

\section{Statistical analysis}

All data are reported as means \pm standard deviations (SD). The significant differences between mean values were determined by Newman and Keuls multiple range test $(\mathrm{p} \leq 0.05)$, following oneway ANOVA. The statistical analysis was performed using Statbox 6.40. T-test was used to determine the significance of difference between the phytotoxicity experiments and the control by STATISTICA version 6 . $\mathrm{P}<0.05$ were taken to be statistically significant.

\section{Results and discussion \\ Yield and chemical composition of EOs}

C. limon and C. sinensis EOs provided a level of about $0.62 \pm 0.13$ and $0.55 \pm 0.05 \%$, respectively. Data were in accordance with the findings of Djenane ${ }^{18}$ who observed that the yield of $C$. limon and C. sinensis EOs was $0.70 \%$ and $0.58 \%$, respectively. However, Tue et al. ${ }^{19}$ reported that the yield of Citrus EOs was differing with individual plant species ranging from 0.2 to $2.0 \%$. Ahmad et al. ${ }^{20}$ reported that $C$. limon EO yield was $1.12 \%$. Sharma and Tripathi ${ }^{21}$ found that $C$. sinensis EOs yielded $1.8 \%$.

The constituents identified by GC-MS analysis, their retention indices and relative proportions are summarised in Table 1. In the present investigation, the GC-MS analysis showed that 
Table 1. Chemical composition of $C$. sinensis and C. limon EOs

\begin{tabular}{|c|c|c|c|c|}
\hline \multirow[b]{2}{*}{ Components $^{\mathrm{a}}$} & \multirow[b]{2}{*}{$\mathbf{R} \mathbf{I}_{\mathbf{E}}$} & \multirow[b]{2}{*}{$\mathbf{R I}_{\mathbf{L}}$} & \multicolumn{2}{|c|}{$\%$} \\
\hline & & & C. sinensis & C. limon \\
\hline trans-2-Hexenal & 833 & 846 & $\operatorname{tr}$ & - \\
\hline$\alpha$-Thujene & 918 & 924 & $\operatorname{tr}$ & 0.19 \\
\hline$\alpha$-Pinene & 926 & 932 & 0.43 & 0.85 \\
\hline Camphene & 943 & 946 & - & $\operatorname{tr}$ \\
\hline Sabinene & 965 & 969 & 0.38 & 0.77 \\
\hline$\beta$-Pinene & 971 & 974 & 0.30 & 5.90 \\
\hline Methylheptenone & 975 & $980^{48}$ & - & $\operatorname{tr}$ \\
\hline Myrcene & 981 & 988 & 1.56 & 1.07 \\
\hline Dehydro-1,8-cineole & 983 & 988 & - & $\operatorname{tr}$ \\
\hline n-Octanal & 998 & 998 & 0.85 & 0.14 \\
\hline$\alpha$-Phellandrene & 1002 & 1002 & $\operatorname{tr}$ & $\operatorname{tr}$ \\
\hline$\delta$-3-Carene & 1004 & 1008 & 0.06 & - \\
\hline$\alpha$-Terpipene & 1011 & 1014 & 0.06 & 0.32 \\
\hline p-Cymene & 1020 & 1020 & - & 0.91 \\
\hline Limonene & 1026 & 1024 & 82.6 & 54.95 \\
\hline trans- $\beta$-Ocimene & 1038 & 1044 & 0.07 & 0.10 \\
\hline$\gamma$-Terpinene & 1051 & 1054 & 0.60 & 7.25 \\
\hline n-Octanol & 1065 & 1063 & 0.08 & 0.09 \\
\hline p-Mentha-3,8-diene & 1074 & 1068 & $\operatorname{tr}$ & - \\
\hline Terpinolene & 1079 & 1086 & 0.11 & 0.71 \\
\hline p-Cymenene & 1085 & 1089 & - & $\operatorname{tr}$ \\
\hline Linalool & 1095 & 1095 & 4.99 & 1.45 \\
\hline n-Nonanal & 1099 & 1100 & 0.26 & 0.23 \\
\hline 1,3,8-p-Menthatriene & 1108 & 1108 & - & 0.05 \\
\hline Methyloctanoate & 1116 & $1116^{49}$ & 0.08 & - \\
\hline cis-p-Menth-2-en-1-ol & 1119 & 1118 & $\operatorname{tr}$ & 0.07 \\
\hline cis-Limoneneoxide & 1131 & 1132 & 0.12 & 0.06 \\
\hline cis-p-Menth-2,8-dien-1-ol & 1134 & 1133 & - & $\operatorname{tr}$ \\
\hline neo-allo-Ocimene & 1137 & 1140 & $\operatorname{tr}$ & 0.08 \\
\hline Camphor & 1141 & 1141 & - & 0.05 \\
\hline 1,4-Dimethyl- $\gamma$-3-tetrahydroacetophenone & 1143 & $1145^{50}$ & - & 0.07 \\
\hline Isopulegol & 1143 & 1145 & $\operatorname{tr}$ & - \\
\hline Citronellal & 1145 & 1148 & 0.29 & 0.33 \\
\hline Isoneral & 1154 & 1160 & - & 0.07 \\
\hline Borneol & 1167 & 1165 & - & 0.08 \\
\hline Terpinene-4-ol & 1175 & 1174 & 0.49 & 1.49 \\
\hline Naphthalene & 1179 & 1178 & $\operatorname{tr}$ & $\operatorname{tr}$ \\
\hline p-Cymene-8-ol & 1183 & 1179 & - & 0.05 \\
\hline n-Butyl n-hexanoate & 1185 & 1186 & $\operatorname{tr}$ & - \\
\hline$\alpha$-Terpineol & 1191 & 1186 & 1.09 & 1.88 \\
\hline cis-Piperitol & 1195 & 1195 & $\operatorname{tr}$ & $\operatorname{tr}$ \\
\hline n-Decanal & 1201 & 1201 & 0.63 & 0.09 \\
\hline trans-Piperitol & 1205 & 1207 & - & 0.05 \\
\hline
\end{tabular}


table 1. (continued).

\begin{tabular}{|c|c|c|c|c|}
\hline \multirow[b]{2}{*}{ Components $^{\mathrm{a}}$} & \multirow[b]{2}{*}{$\mathbf{R I}_{\mathbf{E}}$} & \multirow[b]{2}{*}{$\mathbf{R I}_{\mathbf{L}}$} & \multicolumn{2}{|c|}{$\%$} \\
\hline & & & C. sinensis & C. limon \\
\hline trans-Carveol & 1216 & 1215 & 0.09 & 0.09 \\
\hline Citronellol & 1224 & 1223 & 0.37 & 0.94 \\
\hline Nerol & 1220 & 1227 & 0.16 & 1.61 \\
\hline Neral & 1232 & 1235 & 0.63 & 2.78 \\
\hline Carvone & 1239 & 1239 & 0.10 & 0.19 \\
\hline Geraniol & 1248 & 1249 & 0.15 & 1.45 \\
\hline Methylcitronellate & 1257 & 1257 & $\operatorname{tr}$ & $\operatorname{tr}$ \\
\hline Geranial & 1262 & 1264 & 0.78 & 3.63 \\
\hline Perillaldehyde & 1269 & 1269 & 0.27 & 0.23 \\
\hline o-Acetanisole & 1287 & 1290 & - & $\operatorname{tr}$ \\
\hline Carvacrolethylether & 1297 & 1297 & 0.06 & 0.06 \\
\hline m-Acetylanisole & 1301 & 1298 & - & $\operatorname{tr}$ \\
\hline Carvacrol & 1305 & 1298 & - & $\operatorname{tr}$ \\
\hline p-Vinyl-guaiacol & 1309 & 1309 & $\operatorname{tr}$ & - \\
\hline Methylgeranate & 1315 & $1316^{51}$ & - & $\operatorname{tr}$ \\
\hline Methylcaprinate & 1318 & $1325^{52}$ & $\operatorname{tr}$ & - \\
\hline Citronellylacetate & 1342 & 1350 & - & 0.19 \\
\hline Nerylacetate & 1353 & 1359 & $\operatorname{tr}$ & 1.60 \\
\hline$\alpha$-Copaene & 1367 & 1374 & $\operatorname{tr}$ & - \\
\hline Geranylacetate & 1371 & 1379 & - & 0.78 \\
\hline Ethylcaprate & 1389 & $1380^{53}$ & $\operatorname{tr}$ & - \\
\hline cis- $\alpha$-Bergamotene & 1404 & 1411 & - & 0.11 \\
\hline$\beta$-Caryophyllene & 1410 & 1417 & 0.05 & 0.74 \\
\hline$\beta$-Copaene & 1421 & 1430 & 0.05 & - \\
\hline trans- $\alpha$-Bergamotene & 1428 & 1432 & $\operatorname{tr}$ & 1.12 \\
\hline Geranylpropionate & 1441 & $1444^{54}$ & - & $\operatorname{tr}$ \\
\hline$\alpha$-Humulene & 1447 & 1452 & 0.05 & 0.15 \\
\hline$\beta$-Santalene & 1451 & 1257 & - & 0.06 \\
\hline$\beta$-Acoradiene & 1469 & 1469 & - & $\operatorname{tr}$ \\
\hline trans- $\beta$-Farnesene & 1475 & $1471^{55}$ & - & 0.08 \\
\hline Valencene & 1484 & 1496 & 0.15 & 0.20 \\
\hline Bicyclogermacrene & 1486 & 1500 & - & 0.32 \\
\hline$\alpha$-Muurolene & 1491 & 1500 & $\operatorname{tr}$ & - \\
\hline E,E- $\alpha$-Farnesene & 1498 & 1505 & $\operatorname{tr}$ & 0.18 \\
\hline$\beta$-Bisabolene & 1501 & 1505 & $\operatorname{tr}$ & 2.14 \\
\hline$\delta$-Cadinene & 1510 & 1522 & 0.08 & 0.09 \\
\hline$\beta$-Sesquiphellandrene & 1519 & 1521 & $\operatorname{tr}$ & $\operatorname{tr}$ \\
\hline cis- $\gamma$-Bisabolene & 1533 & 1529 & - & $\operatorname{tr}$ \\
\hline Elemol & 1543 & 1548 & $\operatorname{tr}$ & - \\
\hline trans-Sesquisabinene hydrate & 1578 & 1577 & - & $\operatorname{tr}$ \\
\hline$\gamma$-Eudesmol & 1626 & 1630 & $\operatorname{tr}$ & $\operatorname{tr}$ \\
\hline t-Muurolol & 1638 & 1640 & - & $\operatorname{tr}$ \\
\hline$\alpha$-Cadinol & 1650 & 1652 & 0.02 & 0.05 \\
\hline
\end{tabular}


table 1. (continued).

\begin{tabular}{|lcrrr|}
\hline Components $^{\mathbf{a}}$ & $\mathbf{R I}_{\mathbf{E}}$ & $\mathbf{R I}_{\mathbf{L}}$ & $\boldsymbol{C}$. sinensis & C. limon \\
\hline$\beta$-Bisabolol & 1664 & 1674 & - & 0.06 \\
$\alpha$-Bisabolol & 1683 & 1685 & - & 0.27 \\
$\beta-$-Sinensal & 1686 & 1699 & 0.36 & - \\
$\alpha-$-Sinensal & 1743 & 1755 & 0.11 & - \\
Total identified & & & 99.10 & 99.11 \\
Monoterpene Hydrocarbons & & & 86.25 & 73.27 \\
Oxygen-containing Monoterpenes & & & 9.73 & 19.34 \\
Sesquiterpene Hydrocarbons & & & 0.54 & 5.3 \\
Oxygen-containing Sesquiterpenes & & & 0.55 & 0.44 \\
Others & & & 2.03 & 0.72 \\
\hline
\end{tabular}

${ }^{\mathrm{a}}$ Components listed in order of elution on DB-5 column.

$\mathrm{RI}_{\mathrm{E}}$ - experimentally determined retention indices on the mentioned column by co-injection of a homologous series of $n$-alkanes C8-C28.

$\mathrm{RI}_{\mathrm{L}}$ - literature retention indices $(7,48,49,50,51,52,53,54,55)$. tr- trace $(<0.05 \%)$

different group of terpenoid compounds was present. In C. limon EO, the monoterpene hydrocarbons are mainly represented by limonene $(54.95 \%)$ and the oxygenated monoterpenes were represented by geranial $(3.63 \%)$, neral (2.78\%), $\alpha$-terpineol (1.88\%), nerol (1.61\% \%), neryl acetate $(1.60 \%)$, terpene-4-ol $(1.49 \%)$, geraniol $(1.45 \%)$ and linalool $(1.45 \%)$. However, the sesquiterpene hydrocarbons and oxygenated sesquiterpenes were minor. C. sinensis EO consisted of monoterpene hydrocarbons where the predominant component was limonene (82.6 $\%$ ). The main oxygenated monoterpenes were linalool (4.99\%), $\alpha$-terpineol (1.08\%). The sesquiterpene hydrocarbons and oxygenated sesquiterpenes were in fewer quantities.

These data were somehow similar to the findings of Sharma and Tripathi ${ }^{21}$, where limonene $(84.2 \%)$ and linalool (4.4\%) were the major component in C.sinensis (L.) Osbeck EO composition. Djenane ${ }^{18}$ studied C. sinensis and C. limon peels EOs from Algeria. According to him the main constituent in $C$. sinensis $\mathrm{EO}$ were limonene $(77.37 \%)$ and $\beta$-pinene (3.45\%), whereas, major constituents in $C$. limon EO were limonene $(51.39 \%), \beta$-pinene $(17.04 \%)$ and $\gamma$-terpinene (13.46\%). C. maxima Burm and C. sinensis (L.) Osbeck EOs were also characterized by limonene
(31.83\% and $90.66 \%$, respectively) as predominant component. As well, C.maxima EO was consisted by other constituents such as E-citral (17.75 $\%), 1$-hexene-4-methyl (15.22\%) and Z-citral $(13.38 \%)^{22}$.

This difference among the citrus EOs yield and chemical composition related to variety and age of plant, environmental conditions, harvesting time and extraction method.

\section{Identification of the fungal strain}

Data of the identification exhibited that the fungus used for the present investigation belonged to A. flavus because it showed different colors on the used culture media, which facilitated its identification according to the identification key. Besides, the test of aflatoxinogenicity showed that A.flavus E73 synthesized $\mathrm{AFB}_{1}$.

\section{Antifungal activity assay}

The antifungal activity of $C$. limon and $C$. sinensis EOs for the seven days is presented in Figure 1. Fungal growth was significantly ( $p \leq$ 0.05 ) diminished with increasing concentration of EOs, which indicated dose dependent activity. The percentage inhibition of fungal growth was determined at day 7 (Figure 2). C. limon EO caused $75.14 \%$ inhibition in fungal growth at $1.5 \mathrm{mg} / \mathrm{mL}$ 

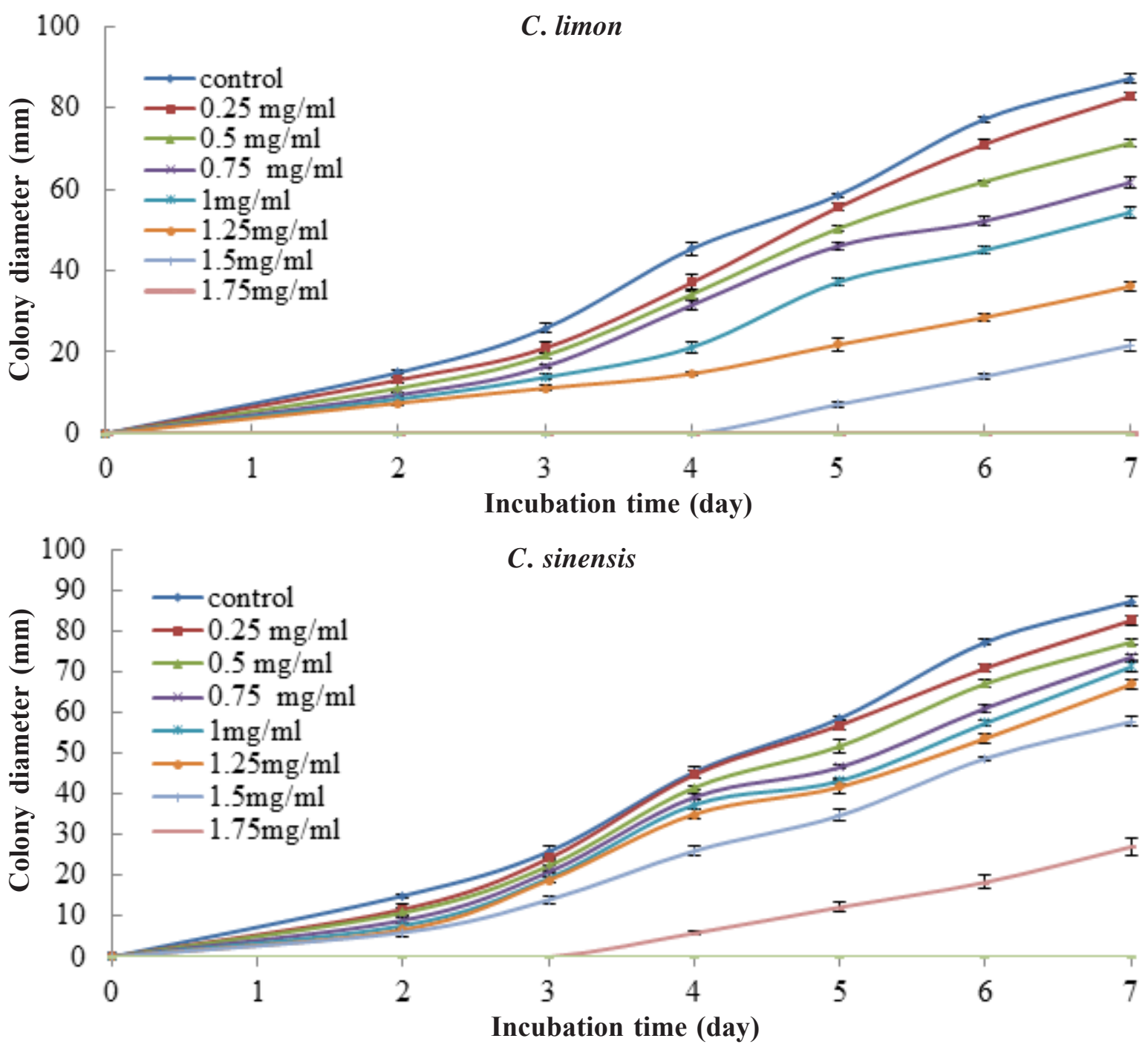

Figure 1. Influence of different concentrations of $C$. limon and C. sinensis EOs on $A$. flavus E73 growth during 7 days

compared with the control $(p \leq 0.05)$. C. limon EO showed complete inhibition of A. flavus E73 at $1.75 \mathrm{mg} / \mathrm{mL}$ and C. sinensis EO provided 68.24 $\%$ inhibition at the same concentration compared with the control $(p \leq 0.05)$.

Despite the low proportion of limonene (54.95 $\%$ ) in C. limon EO when compared to that of C. sinensis $(82.6 \%)$, it showed high antifungal activity against $A$. flavus E73, but it might not be related to this constituent. It has been known that the antifungal activity of this EO was affected by $\gamma$-terpinene, p-cymene ${ }^{23-24}$ and pinenes, which have been shown to have good antifungal activity ${ }^{25}$. Thus, these components could play a significant role in the pronounced activity of $C$. limon
EO. Moreover, the antifungal activity of this EO can be attributed to citronellol, geraniol, $\alpha$-terpineol and nerol. Linalool and terpinen-4-ol exhibited also good activity ${ }^{26}$. Monoterpene alcohols increase the permeability of the plasma membrane and inhibit process of respiration on mitochondrial membrane of fungi ${ }^{27-28}$. However, the antifungal activity of EOs cannot be related to single components because they are constituted by variety of volatile compounds. It is the result of synergistic and antagonistic action of the major and minor constituents of EOs ${ }^{29}$. Therefore, the chances of resistance development in fungi after application of the EO would be reduced, and the sensitivity to its action would be wider. Moreover, the puri- 


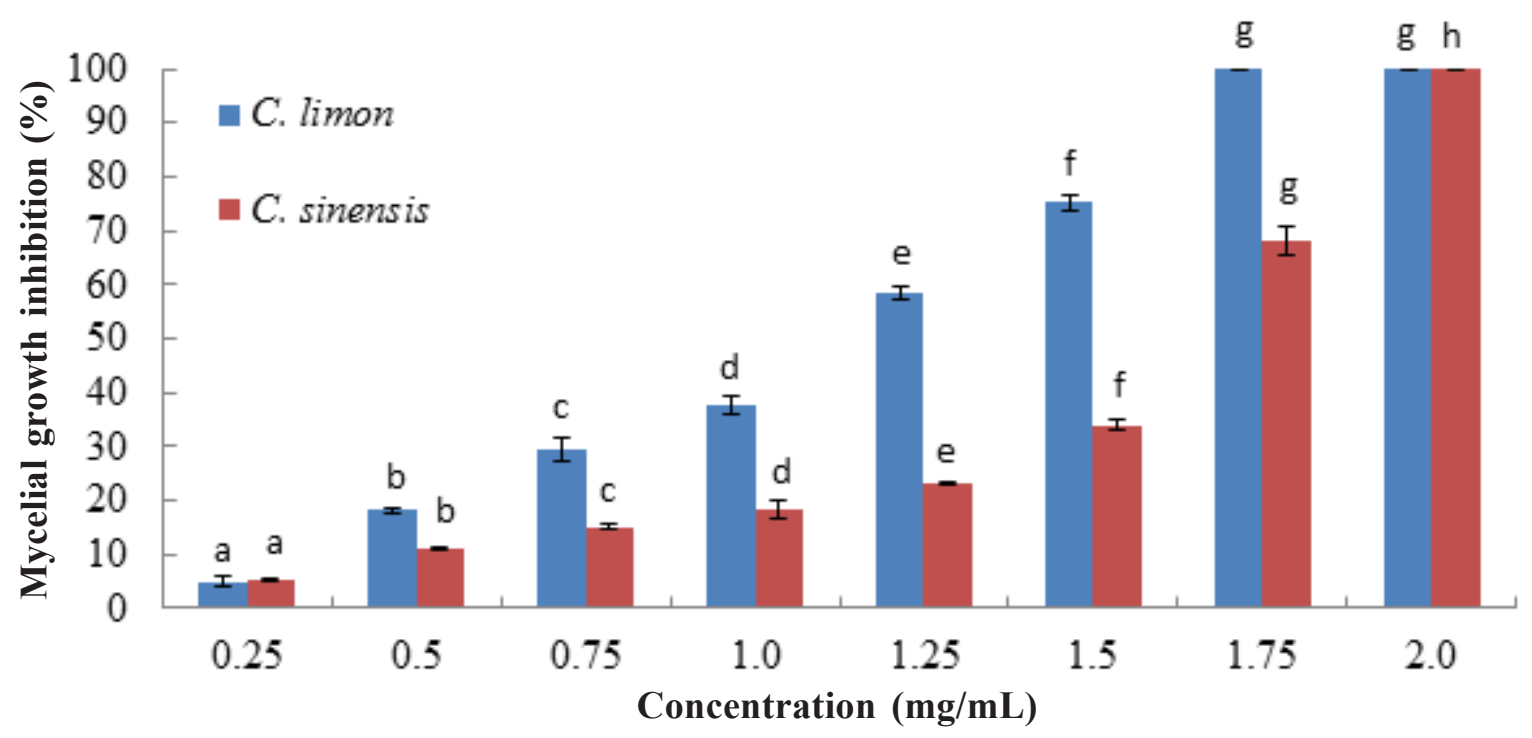

Figure 2. Percentage inhibition of A.flavus E73 growth after 7-day.

Columns with the different letters are significantly different $(p \leq 0.05)$

fication of the individual compounds would require higher costs, so whole EOs appeared to be more promising in commercial application than single compounds.

The study of MIC and MFC is important to determine the minimum dose to control fungal populations ${ }^{30}$. The MIC/MFC test has been assessed against $A$. flavus $\mathrm{E} 73$ by the broth dilution method using SMKY medium. Kalemba and Kunicka ${ }^{31}$ reported that the method gives opportunity to EOs to come in close contact with fungal spores in the medium. The MIC against $A$. flavus E73 was recorded at $1.75 \mathrm{mg} / \mathrm{mL}$ for $C$. limon and $2 \mathrm{mg} / \mathrm{mL}$ for $C$. sinensis. The EOs of $C$. limon and $C$. sinensis at these two concentrations, completely inhibited the growth of the fungal strain. The MFC of C. limon and C. sinensis occurred at $2 \mathrm{mg} / \mathrm{mL}$ and $2 \mathrm{mg} / \mathrm{mL}$, respectively.

Data showed that the MIC of the used EOs in the present study was lower than $C$. sinensis var. Valencia ${ }^{11}$ and were higher than the C. maxima Burm. and C. sinensis (L.) Osbeck ${ }^{22}$. It should be noted that the variation in MIC of EOs can be explained by the difference in the chemical con-stituents, the test fungus and the medium chosen for evaluating of antifungal activity.

Efficacy of the EOs on dry mycelium weight and $A F B$ content

The effect of the EOs of C. limon and $C$. sinensis on mycelium dry weight and $\mathrm{AFB}_{1}$ production $(p \leq 0.05)$ is presented in Figure 3. It can be clearly seen that $C$. limon EO showed marked inhibition of mycelium dry weight and $\mathrm{AFB}_{1}$ at all concentrations where complete inhibition was observed at $1.75 \mathrm{mg} / \mathrm{mL}$. While, for EO of $C$. sinensis, the complete inhibition was observed at $2 \mathrm{mg} / \mathrm{mL}$.

C. limon and C. sinensis EOs can inhibit mycelium dry weight and the $\mathrm{AFB}_{1}$ production. A direct correlation between fungal growth and $\mathrm{AFB}_{1}$ synthesis has been observed. Reddy et al. ${ }^{32} \mathrm{re}-$ vealed that Syzigium aromaticum EO at $5 \mathrm{~g} / \mathrm{kg}$ inhibited A. flavus growth and $\mathrm{AFB}_{1}$ production. Whereas, Caesulia axilaris Roxb. EO showed quite inhibition of the $A$. flavus growth at $1.0 \mu \mathrm{L} /$ $\mathrm{mL}$ and $\mathrm{AFB}_{1}$ production at $0.8 \mu \mathrm{L} / \mathrm{mL}^{33}$. Furthermore, Vilela et al. ${ }^{34}$ indicated that inhibition of $\mathrm{AFB}_{1}$ produced by A. flavus and A. parasiticus with Eucalyptus globulus EO needed higher concentration than that for fungal growth inhibition. From the findings presented by these authors, it is clear that the inhibition of $\mathrm{AFB}_{1}$ cannot be totally attributed to fungal growth inhibition. The interference with some key enzymes of carbohydrate catabolism pathway in A. flavus, decreased its potential to produce $\mathrm{AFB}_{1}{ }^{13}$. Thereby, C. limon and $C$. sinensis EOs could act in the same manner to control the synthesis of $\mathrm{AFB}_{1}$ by the A. flavus E73. Further research is required in 

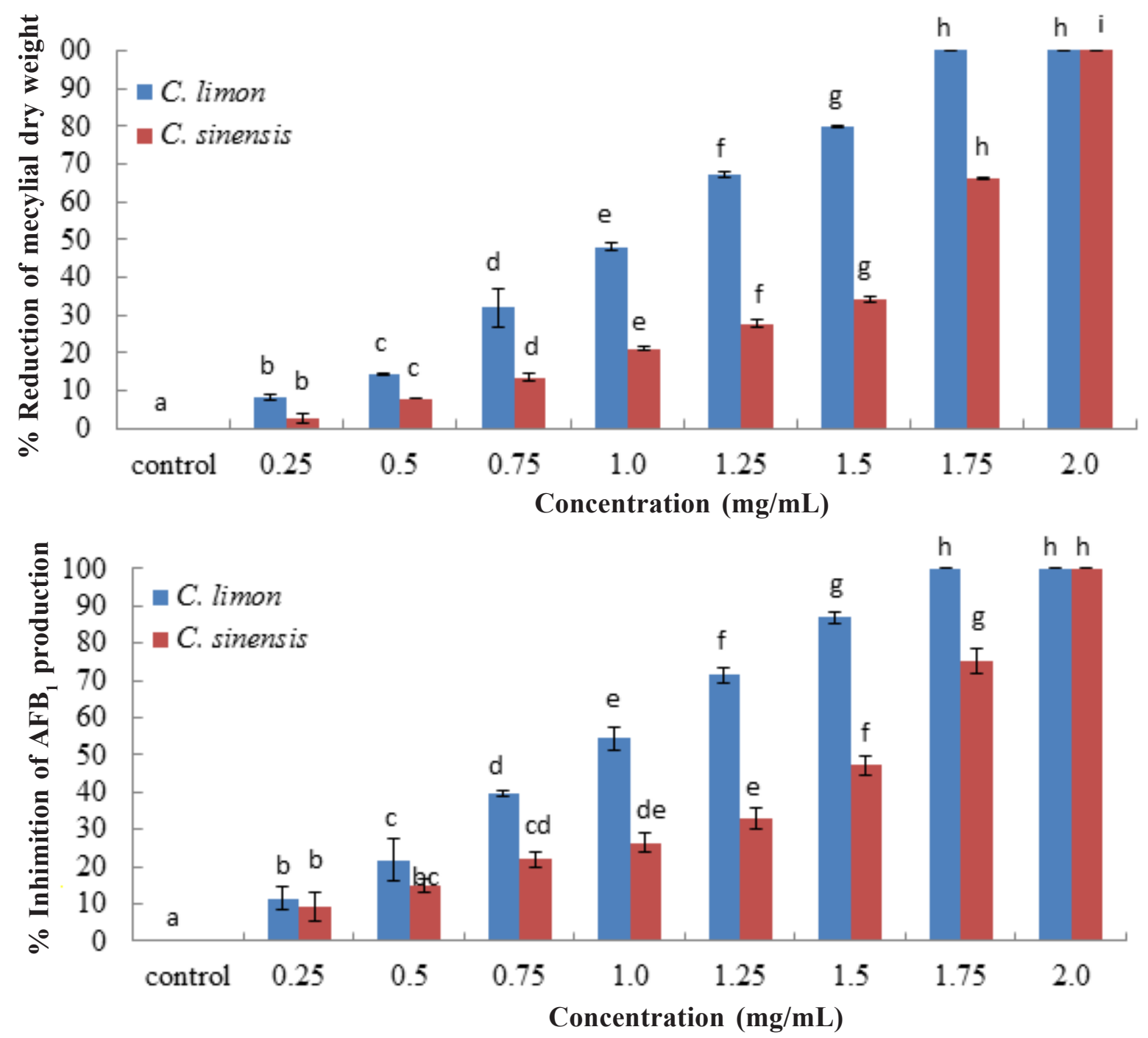

Figure 3. Effect of EOs on mycelia dry weight and $\mathrm{AFB}_{1}$ production by A. flavus E73.

Columns with the same letters are not significantly different. Values are mean $(n=3) \pm S D$

order to understand mechanisms action for the control of $\mathrm{AFB}_{1}$ production because the majority of previous works focus more on the detection of EOs' antifungal and antiaflatoxin activity, hence, the mechanisms of action are poorly studied, most of which are assumptions.

\section{Spectrum of fungitoxicity}

The spectrum of fungitoxicity at different concentrations against the isolated fungi has been also investigated. Data of the activity of C. limon and C. sinensis EOs are presented in Table 2. They showed complete inhibition of growth of all the fungi studied. C. limon EO was more effective, which inhibited the growth of most fungi.
Fusarium sp. and Rhizopus sp. (1.75 mg/mL) necessitated the highest concentration of this EO for inhibition and the lowest was for $A$. terreus $(0.75 \mathrm{mg} / \mathrm{mL})$. Results indicated that C. limon EO showed lower inhibitory concentration compared to $C$. sinensis EO except $A$. niger and Fusarium sp., where the inhibition was the same (1.5 and $1.75 \mathrm{mg} / \mathrm{mL}$, respectively). A. ochraceus was in-hibited at $2 \mathrm{mg} / \mathrm{mL}$ of $C$. sinensis $\mathrm{EO}$, which made it the most resistant to this EO compared to the other tested fungi. As well, MFC was determined for $C$. limon and $C$. sinensis EOs. It should be noted that MFC values were higher than these of MIC, they were between 1 and > $2 \mathrm{mg} / \mathrm{mL}$ for both EOs. 
Table 2. Spectrum of fungitoxicity of $C$. sinensis and $C$. limon EOs

\begin{tabular}{|lcccc|}
\hline & \multicolumn{2}{c}{ CMI (mg/mL) } & \multicolumn{2}{c|}{ CMF (mg/mL) } \\
Fungi & C. limon & C. sinensis & C. limon & C. sinensis \\
\hline A. carbonarius & $1.0 \pm 0.00$ & $1.75 \pm 0.25$ & $1.25 \pm 0.5$ & $>2.0$ \\
A. fumigatus & $1.0 \pm 0.43$ & $1.5 \pm 0.00$ & $1.5 \pm 0.25$ & $1.75 \pm 0.00$ \\
A. niger & $1.5 \pm 0.00$ & $1.5 \pm 0.14$ & $1.75 \pm 0.00$ & $2.0 \pm 0.00$ \\
A. ochraceus & $1.5 \pm 0.00$ & $2.0 \pm 0.00$ & $2.0 \pm 0.00$ & $>2.0$ \\
A. tamarii & $1.25 \pm 0.25$ & $1.5 \pm 0.72$ & $1.75 \pm 0.00$ & $1.75 \pm 0.00$ \\
A. terreus & $0.75 \pm 0.25$ & $1.75 \pm 0.00$ & $1.0 \pm 0.25$ & $1.75 \pm 0.43$ \\
Fusarium sp. & $1.75 \pm 0.00$ & $1.75 \pm 0.00$ & $2 \pm 0.00$ & $>2.0$ \\
Penicillium sp. & $1.5 \pm 0.43$ & $1.75 \pm 0.00$ & $1.75 \pm 0.00$ & $>2.0$ \\
Rhizopus sp. & $1.75 \pm 0.00$ & $2.00 \pm 0.00$ & $>2.0$ & $>2.0$ \\
\hline
\end{tabular}

Values are given as means of three repetitions

A lot of research has investigated the fungitoxicity potential of Citrus EOs. Sharma and Tripathi

${ }^{21}$ in their work reported that $C$. sinensis (L.) Osbeck EO was found to be fungicidal against $A$. niger. Viuda-Martos et al. ${ }^{35}$, reported that the EOs of lemon, orange, mandarin and grapefruit peels showed, the potential to inhibit the growth of Penicillium chrysogenum, Penicillium verrucosum, A. niger and A. flavus. Singh et al. ${ }^{22}$, in their work reported that $C$. maxima Burm. and C. sinensis (L.) Osbeck EOs was found to be fungicidal against $A$. fumigatus, $A$. niger, A. terreus, Alternaria alternata, Cladosporium herbarum, Curvularia lunata, Fusarium oxysporum, Helminthosporium oryzae and Trichoderma viride. In this investigation, the fungitoxicity of C. limon and C. sinensis EOs has been mainly tested on Aspergillus genera because they are frequent contaminants of medium and low moisture food. Metabolic activity of these microorganisms causes food spoilage and biosynthesize toxic secondary metabolites-mycotoxins: aflatoxins, ochratoxin A. C. limon and C. sinensis EOs has been also tested on Fusarium and Penicillium for their capability to synthesize mycotoxins as zearalenone, citrinin, ochratoxin A, fumonisin, patulin and deoxynivalenol. These toxigenic fungi should be studied in depth with regard to use Citrus EOs. Hence, C. limon and C. sinensis EOs would be necessitated for inhibition of the fungal contamination of foods.
Total phenolic content and antioxidant capacity

Data from the determination of total phenolic content of C. limon and C. sinensis EOs are summarized in Table 3. The total phenolic contents varied significantly $(p<0.05)$ between the two studied EOs, C. limon had higher total phenolic content $(16.90 \mu \mathrm{g} / \mathrm{mg})$ than C. sinensis $(10.53 \mu \mathrm{g} /$ $\mathrm{mg})$. The antioxidant activity of $C$. limon and $C$. sinensis EOs were also tested. The concentrations that led to $\mathrm{IC}_{50}$ and the $\beta$-carotene oxidation inhibition $C$. limon and $C$. sinensis oils were 1570.10 and $752.26 \mu \mathrm{g} / \mathrm{mg} ; 36.19$ and $55.56 \%$, respectively $(p \leq 0.05)$ (Table 3$)$.

Previous studies showed a significant correlation between the antioxidant activity and total phenolic contents in herbs, vegetables and fruits ${ }^{36-37}$. In comparison with the obtained data, Prakash at $a l .{ }^{38}$ in his study found that the antioxidant activity of Cananga odorata EO was higher than Commiphora myrrha EO, although C. myrrha presented greater total phenolic content. Thus, antioxidant activity cannot be related to just phenolics.

Data of antioxidant activity exhibited a difference in DPPH radical scavenging between C. limon and C. sinensis EOs. This difference could be explained by the chemical composition of each EO. Additionally, free radical scavenging activity of EO may be attributed to the phenolic compounds presented in these EOs because it has 
Table 3. Antioxidant activity and total phenolic of $C$. sinensis and $C$. limon EOs.

\begin{tabular}{|lrcc|}
\hline EOs & $\begin{array}{c}\text { DPPH }\left(\mathbf{I C}_{\mathbf{5 0}}\right) \\
(\boldsymbol{\mu g} / \mathbf{m L})\end{array}$ & $\begin{array}{c}\boldsymbol{\beta} \text {-carotene/Linoleic } \\
\text { acid inhibition }(\mathbf{\%})\end{array}$ & $\begin{array}{c}\text { Total phenolic content } \\
(\boldsymbol{\mu} \mathbf{g} / \mathbf{m g})\end{array}$ \\
\hline C. limon & $1570.10 \pm 19.57^{\mathrm{a}}$ & $36.19 \pm 0.64^{\mathrm{a}}$ & $16.90 \pm 0.24^{\mathrm{a}}$ \\
C. sinensis & $752.26 \pm 6.09^{\mathrm{b}}$ & $55.56 \pm 0.64^{\mathrm{b}}$ & $10.53 \pm 0.26^{\mathrm{b}}$ \\
BHT & $306.15 \pm 4.49^{\mathrm{c}}$ & $94.77 \pm 1.61^{\mathrm{c}}$ & $\mathrm{nd}$ \\
\hline
\end{tabular}

nd: not determined

Means in each column followed by different letters are significantly different $(p \leq 0.05)$

been reported that they have antioxidant activities against reactive oxygen species (ROS), or the interactions between the whole compounds ${ }^{39-40}$. On the other hand, the oxidation of $\beta$-carotene was considerably inhibited by C. limon and C. sinensis EOs. Jayashree and Subramanyam ${ }^{41}$ in their investigation reported that oxidative stress causes $\mathrm{AFB}_{1}$ production by Aspergillus spp. In later works, other authors as Narasaiah et al. ${ }^{42}$; Zjalic et al..$^{43}$ and Kim et al. ${ }^{44}$, proved that biosynthesis of aflatoxins is really related to oxidative stress and peroxidation. Ferreira et al. ${ }^{2}$ reported that the efficacy of Curcuma longa L. and curcumin on aflatoxins production may be attributed to the inhibition ternary steps of aflatoxins synthesis, lipid peroxidation and oxygenation. Hua et al. ${ }^{45}$ showed that phenolics reveal inhibitory activity on $\mathrm{AFB}_{1}$ production by $A$. flavus. Thereby, the efficacy of $C$. limon and $C$. sinensis EOs on $\mathrm{AFB}_{1}$ production may be related to their antioxidant nature.

\section{Phytotoxicity assay}

During this investigation, the effects of C. limon and $C$. sinensis EOs on the germination and seedling growth of AS 81189 A (Ain Abid) and HD 1220 (Hiddab) were evaluated. As shown in Table 4, C. limon and C. sinensis EOs diminished significantly the germination of AS 81189 A (Ain Abid) seeds compared to the control $(<0.05)$, while, no significant decrease for HD1220 (Hiddab) seeds compared to the control $(>0.05)$. The length of radicles of AS 81189 A (Ain Abid) was significantly diminished in the seeds treated with $C$. limon and $C$. sinensis EOs $(p<0.05)$, but the effect of EOs on the length of plumules of AS 81189 A (Ain Abid), radicles and plumules of HD1220 (Hiddab) was non significative compared to the control $(>0.05)$.

C. limon and C. sinensis EOs did not exhibit a potent phytotoxicity. Thus, the EOs may be only recommended for food commodities stored for

Table 4. Influence of $C$. limon and $C$. sinensis EOs on seed germination and seedling growth

\begin{tabular}{|c|c|c|c|}
\hline \multirow[b]{2}{*}{ Samples } & \multirow[b]{2}{*}{ Germination (\%) } & \multicolumn{2}{|c|}{ Seedling growth (mm) } \\
\hline & & Radicle & Plumule \\
\hline \multicolumn{4}{|c|}{ HD1220 (Hiddab) } \\
\hline C. limon EO & $80.00 \pm 4.00$ & $52.66 \pm 3.92$ & $43.70 \pm 1.70$ \\
\hline C. sinensis EO & $77.33 \pm 3.05$ & $45.50 \pm 1.81$ & $38.50 \pm 2.50$ \\
\hline Control & $92.66 \pm 3.05$ & $67.70 \pm 2.98$ & $57.83 \pm 1.30$ \\
\hline \multicolumn{4}{|c|}{ AS 81189 A (Ain Abid) } \\
\hline C. limon EO & $72.66 \pm 3.0$ & $60.06 \pm 4.24$ & $52.96 \pm 6.16$ \\
\hline C. sinensis EO & $571.33 \pm 3.05$ & $59.73 \pm 2.07$ & $49.03 \pm 2.25$ \\
\hline Control & $90.66 \pm 4.16$ & $69.40 \pm 2.98$ & $60.30 \pm 4.59$ \\
\hline
\end{tabular}


consumption purpose.

Many authors studied the phytotoxicity of some EOs. Five plants (Origanum majorana L., Coriandrum sativum L., Hedychium spicatum, Commiphora myrrha, and Cananga odorata) were tested for their phytotoxicity on chickpea. They were found to be non phytotoxic ${ }^{38}$. Shukla et al. ${ }^{46}$ tested the effect of Callistemon lanceolatus EO and its major component 1,8-cineole on chickpea seed germination.

The authors noted that there was no adverse effect, suggesting their non-phytotoxic nature. Similar type of results were obtained by Kedia et $a l .{ }^{47}$, who reported that cumin EO revealed no phytotoxic effect on germination of wheat and chickpea seed. Until now, there are no published data on the effect of Citrus EOs and particularly Citrus limon var. Eureka and Citrus sinensis var. Valencia EOs on the germination and seedling growth of wheat.

\section{Conclusion}

The Algerian C. limon and C. sinensis EOs can inhibit fungal growth and $\mathrm{AFB}$, production. They also showed fungitoxic spectrum against some isolated fungi, antioxidant activity and phytotoxicity. These findings should be taken into consideration by industries to exploit Citrus EOs as natural food additives for food items.

\section{Acknowledgements}

We are thankful to Mr Tarek Benabdelkhader and Laboratoire de Biotechnologies Végétales appliquées aux plantes aromatiques et médicinales (BVpam) de la Faculté des Sciences et Techniques de Saint Etienne, France for Gas chromatography-mass spectrometry (GC-MS) analsis and to Omrane Toumatia for the statistical analysis. Thanks to the Grupo de Investigación A06_17R (Gobierno de Aragón-FEDER, Spain) for financial support.

\section{References}

1. Nguefack, J., Dongmo, J.B.L., Dakole, C.D., Leth, V., Vismer, H.F., Torp, J. et al. (2009). Food preservative potential of essential oils and fractions from Cymbopogon citratus, Ocimum gratissimum and Thymus vulgaris against mycotoxigenic fungi. Int. J. Food Microbiol. 131: 151156.

2. Ferreira, F.D., Kemmelmeier, C., Arrotéia, C.C., da Costa, L.C., Mallmann, C.A., Janeiro, V., Ferreira, F.M.D., Mossini, S.A.G., Silva, E.L. and Machinski, M. (2013). Inhibitory effect of the essential oil of Curcuma longa L. and curcumin on aflatoxin production by Aspergillus flavus Link. Food Chem. 136: 789-793.

3. Shukla, R., Kumar, A., Singh, P. and Dubey, N.K. (2009). Efficacy of Lippia alba (Mill.) N.E. Brown essential oil and its monoterpene aldehyde constituents against fungi isolated from some edible legume seeds and aflatoxin B1 production. Int. J. Food Microbiol. 135: 165-170.

4. Razzaghi-Abyaneh, M., Shams-Ghahfarokhi, M., Bagher Rezaee, M., Jaimand, K., Alinezhad, S., Saberi, R. and Yoshinari, T. (2009). Chemical composition and antiaflatoxigenic activity of Carum carvi L., Thymus vulgaris and Citrus aurantifolia essential oils. Food control. 1018-1024.

5. Tzortzakis, N.G. (2009). Impact of cinnamon oil-enrichment on microbial spoilage of fresh produce. Innov. Food Sci and Emerg. Technol. 10 : 97-102

6. Burt, S. (2004). Essential oils: their antibacterial properties and potential applications in foods: a review. Int. J. Food Microbiol. 94: 223-253.

7. Adams, R.P. (2007). Identification of essential oil components by gas chromatography/mass spectrometry. Carol Stream, IL, USA: Allured Publishing Corporation.

8. Pitt, J.I. and Hocking, A.D. (1997). Fungi and food spoilage. Blackie Academic and Professional, London.

9. Mishra, P.K., Singh, P., Prakash, B., Kedia, A. and Dubey, N.K. (2013). Assessing essential oil components as plant-based preservatives against fungi that deteriorate herbal raw materials. Int. Biodeter. Biodegr. 80: 16-21. 
10. Singh, P., Srivastava, B., Kumar, A., Kumar, R., Dubey, N.K. and Gupta, R. (2008). Assessment of Pelargonium graveolens oil as plant-based antimicrobial and aflatoxin suppressor in food preservation. J .Sci. Food Agric. 88: 2421-2425.

11. José Velázquez-Nuñez, M., Avila-Sosa, R., Palou, E. and López-Malo, A. (2013). Antifungal activity of orange (Citrus sinensis var. Valencia) peel essential oil applied by direct addition or vapor contact. Food Control. 31: 1-4.

12. Shukla, R., Kumar, A., Prasad, C.S., Srivastava, B. and Dubey, N.K. (2008). Antimycotic and antiaflatoxigenic potency of Adenocalymma alliaceum Miers. on fungi causing biodeterioration of food commodities and raw herbal drugs. Int. Biodeter. Biodegr. 62: 348-351.

13. Tian, J., Huang, B., Luo, X., Zeng, H., Ban, X., J, He. and Wang Y. (2012). The control of Aspergillus flavus with Cinnamomum jensenianum Hand.-Mazz essential oil and its potential use as a food preservative. Food Chem, 130: 520-527.

14. Dewanto, V., Wu, X., Adom, K.K. and Liu, R.H. (2002). Thermal processing enhances the nutritional value of tomatoes by increasing total antioxidant activity. J. Agr. Food Chem. 50: 3010-3014.

15. Brand-Williams, W., Cuvelier, M. E. et al. (1995). Use of a free radical method to evaluate antioxidant activity. Lebensm Wiss. Technol, 28: 25-30.

16. Miraliakbari, H. and Shahidi, F . (2008). Antioxidant activity of minor components of tree nut oils. Food Chem. 111 (2): 421-427.

17. Kordali, S., Cakir, A., Ozer, H., Cakmakci, R., Kesdek, M. and Mete, E. (2008). Antifungal, phytotoxic and insecticidal properties of essential oil isolated from Turkish Origanum acutidens and its three components, carvacrol, thymol and p-cymene. Bioresource Technol. 99: 8788-8795.

18. Djenane, D. (2015). Cheminal profile, Antimicrobial and Antioxidant Activity of Algerian Citrus Essential Oils and Their Application in Sardina pilchardus. Foods. 4: 208-228.

19. Tu, M.N.T., Onishi, Y., Choi, H.S., Kondo, Y., Bassore, S.M., Ukeda, H. and Sawamura, M. (2002). Characteristic odor components of Citrus sphaerocarpa Tanaka (Kabosu) coldpressed peel oil. J. Agr. Food Chem. 50: 2908-2913.

20. Ahmad, M.M., Rehman, S., Iqbal, Z., Anjum, F.M. and Sultan, J.I. (2006). Genetic variability to essential oil composition in four citrus fruit species. Pak. J. Bot. 38: 319-324.

21. Sharma, N. and Tripathi, A. (2008). Effects of Citrus sinensis (L.) Osbeck epicarp essential oil on growth and morphogenesis of Aspergillus niger (L.) Van Tieghem. Microbiol. Res. 163: 337-344.

22. Singh, P., Shukla, R ., Prakash, B ., Kumar, A., Singh, S., Mishra, K.P. and Dubey, N.K. (2010). Chemical profile, antifungal, antiaflatoxigenic and antioxidant activity of Citrus maxima Burm. and Citrus sinensis (L.) Osbeck essential oils and their cyclic monoterpene, DL-limonene. Food Chem. Toxicol. 48: 1734-1740.

23. Filipowicz, N., Kaminski, M., Kurlenda, J., Asztemborska, M. and Ochocka, J.R. (2003). Antibacterial and antifungal activity of juniper berry oil and its selected components. Phytother. Res. 17: 227-231.

24. Terzi, V., Morcia, C., Faccioli, P., Vale, G., Tacconi, G. and Malnati, M. (2007). In vitro antifungal activity of the tea tree (Melaleuca alternifolia) essential oil and its major components against plant pathogens. Lett. Appl. Microbiol. 44: 613-618.

25. Souza, E.L.D., Lima E.D.O., Freire, K.R.D.L. and Sousa, C.P.D. (2005). Inhibitory action of some essential oils and phytochemicals on the growth of various moulds isolated from foods. Braz. Arch .Biol .Technol. 48: 245-250.

26. Hammer, K., Carson C. and Riley, T. (2003). Antifungal activity of the components of Melaleuca alternifolia (tea tree) oil. J. Appl. Microbiol. 95(4): 853-860.

27. Cox, D., Mann, M., Markham, L., Bell, C., Gustafson, E., Warmington, R. and Wyllie, G. 
(2000). The mode of antimicrobial action of the essential oil of Melaleuca alternifolia (tea tree oil). J. App. Microbiol. 88: 170-175.

28. Deba, F., Xuan, T., Yasuda, M. and Tawata, S. (2008). Chemical composition and antioxidant, antibacterial and antifungal activities of the essential oils from Bidens pilosa Linn. var. Radiata. Food Contr. 19: 346-352.

29. Chao, L.K., Hua, K.F., Hsu, H.Y., Cheng, S.S., Lin, J.Y. and Chang, S.T. (2005). Study on the anti-inflammatory activity of essential oil from leaves of Cinnamomum osmophloeum. J. Agr. Food Chem. 53: 7274-7278.

30. Kumar, A., Shukla, R., Singh, P., Prasad, C.S. and Dubey, N.K. (2008). Assessment of Thymus vulgaris L. essential oil as a safe botanical preservative against post harvest fungal infestation of food commodities. Innov. Food. Sci. Emerg. Technol. 9: 575-580.

31. Kalemba, D. and Kunicka, A. (2003). Antibacterial and antifungal properties of essential oils. Curr. Med. Chem. 10: 813-829.

32. Reddy, K.R.N., Reddy, C.S. and Muralidharan, K. (2009). Potential of botanicals and biocontrol agents on growth and aflatoxin production by Aspergillus flavus infecting rice grains. Food Control. 20: 173-178.

33. Mishra, P.K., Shukla, R., Singh, P., Prakash, B. and Dubey, N.K. (2012). Antifungal and antiaflatoxigenic efficacy of Caesulia axillaris Roxb. Essential oil against fungi deteriorating some herbal raw materials, and its antioxidant activity. Ind . Crops Prod. 36: 74- 80.

34. Vilela, G.R., de Almeida, G.S ., D’Arce, M.A.B.R., Moraes, M.H.D., Brito, J.O., da Silva, M.F.d.G.F., Silva, S.C., de Stefano Piedade, S.M., Calori-Domingues, M.A. and da Gloria, E.M. (2009). Activity of essential oil and its major compound, 1,8-cineole, from Eucalyptus globulus Labill., against the storage fungi Aspergillus flavus Link and Aspergillus parasiticus Speare. J. Stored Prod. Res. 45: 108-111.

35. Viuda-Martos, M., Ruiz-Navajas, Y., Fernández-López, J. and Pérez-Álvarez, J. (2008). Antifungal activity of lemon (Citrus lemon L.), mandarin (Citrus reticulata L.), grapefruit (Citrus paradisi L.) and orange (Citrus sinensis L.) essential oils. Food Control. 19: 1130-1138.

36. Velioglu, Y.S., Mazza, G., Gao, L. and Oomah, B.D. (1998). Antioxidant activity and total phenolics in selected fruits, vegetables, and grain products. J. Agr. Food Chem. 46: 4113-4117.

37. Dorman, H.J.D., Bachmayer, O., Kosar, M. and Hiltunen R. (2004). Antioxidant properties of aqueous extracts from selected Lamiaceae species grown in Turkey. J. Agr. Food Chem. 52: 762-770.

38. Prakash, B., Singh P., Kedia, A. and Dubey, N.K. (2012). Assessment of some essential oils as ood preservatives based on antifungal, antiaflatoxin, antioxidant activities and in vivo efficacy in food system. Food Res. Int. 49: 201-208.

39. Lu, Y. and Foo, L.Y. (2000). Antioxidant and radical scavenging activities of polyphenols from apple pomace. Food Chem. 68: 81-85.

40. Sreenivasulu, N., Grimm, B., Wobus, U. and Weschke, W. (2000). Differential response of antioxidant compounds to salinity stress in salt-tolerant and salt-sensitive seedlings of foxtail millet (Setaria italica). Plant Physiol. 109:435-442.

41. Jayashree, T. and Subramanyam, C. (2000). Oxidative stress as a prerequisite for aflatoxin production by Aspergillus parasiticus. Free Radical. Bio. Med. 29: 981-985.

42. Narasaiah, K.V., Sashidhar, R. and Subramanyam, C. (2006). Biochemical analysis of oxidative stress in the production of aflatoxin and its precursor intermediates. Mycopathologia. 162: 179189.

43. Zjalic, S., Reverberi, M., Ricelli, A., Granito, V.M., Fanelli, C. and Fabbri, A.A. (2006). Trametes versicolor: A possible tool for aflatoxins control. Int. J. Food Microbiol. 107: 243-246.

44. Kim, J.H., Yu, J., Mahoney, N., Chan, K.L., Molyneux, R.J., Varga, J. et al. (2008). 
Elucidation of the functional genomics of antioxidant-based inhibition of aflatoxin biosynthesis. Int. J. Food Microbiol. 122: 49-60.

45. Hua, S.S.T., Grosjean, O.K. and Baker J.L. (1999). Inhibition of aflatoxin biosynthesis by phenolic compounds. Lett. Appl. Microbiol. 29: 289-291.

46. Shukla, R., Singh, P., Prakash, B. and Dubey, N.K. (2012). Antifungal, aflatoxin inhibition and antioxidant activity of Callistemon lanceolatus (Sm.) Sweet essential oil and its major component 1,8-cineole against fungal isolates from chickpea seeds. Food Control. 25:27-33.

47. Kedia, A., Prakash, B., Mishra, P.K. and Dubey, N.K. (2014). Antifungal and antiaflatoxigenic properties of Cuminum cyminum (L.) seed essential oil and its efficacy as a preservative in stored commodities. Int. J. Food Microbiol. 168-169, 1-7.

48. Saroglou, V., Arfan, M., Shabir, A., Hadjipavlou-Litina, D. and Skaltsa H. (2007). Composition and antioxidant activity of the essential oil of Teucriumroyleanum Wall. Ex Benth growing in Pakistan. Flavour Frag. J. 22 (2): 154-157.

49. Wu, P., Kuo, M. C., Hartman, T.G., Rosen, R.T. and Ho, C.T. (1991). Free and glycosidically bound aroma compounds in pineapple (Ananascomosus L. Merr.). J. Agr. Food Chem. 39(1): 170-172.

50. Vérité, P., Nacer, A., Kabouche, Z. and Seguin E. (2004). Composition of seeds and stems essential oils of Pituranthosscoparius (Coss. Dur.) Schinz Flavour. Frag. J. 19: 562-564.

51. Verzera, A., Trozzi, A., Zappala, M., Condurso, C. and Cotroneo A. (2005). Essential Oil Composition of Citrus meyerii Y. Tan. and Citrus medica L. cv. Diamante and Their Lemon Hybrids. J. Agr. Food Chem. 53(12): 4890-4894.

52. Saroglou, V., Dorizas, N., Kypriotakis, Z. and Skaltsa, H.D. (2006). Analysis of the essential oil composition of eight Anthemis species from Greece. J. Chromatogr. A. 1104(1-2): 313-322.

53. Fang, Y. and Qian, M. (2005). Aroma compounds in Oregon Pinot Noir wine determined by aroma extract dilution analysis (AEDA). Flavour Frag. J. 20 (1): 22-29.

54. BinJantan, I., Yassin, M.S.M., Chin, C.B., Chen, L.L. and Sim, N.L. (2003). Antifungal activity of the essential oils of nine Zingiberaceae species. Pharm. Biol. 41(5): 392-397.

55. Chosson, E., Vérité, P., Blanckaert, A., Seguin, E., Litaudon, M. and Sévenet, T. (2003). Non polar compounds from the bark of Sarcomelicope follicularis. Biochem. Syst. Ecol. 31(10): 1185-1188. 